\title{
The Role of Corporate Communication in Handling Organizational Crisis with 2 Case Studies from the Petroleum and Natural Gas Industry
}

Debatree Saha*

ABP Pvt Ltd, Prafulla Sarkar Street, Kolkata, West Bengal, Kolkata, India

\begin{abstract}
Technology has spread to all spheres of life and Public Sector Units (PSUs) are not lacking behind. The Corporate Communication team in any PSUs uses latest technologies like the new media along with newspapers, televisions, Press Releases etc. to reach out to the masses about the goals and achievements of the organization. This research paper focuses on the role played by the Corporate Communication department in handling organizational crisis that happened in 2005 and 2009 in a reputed Fortune 500 oil sector PSU based in India and abroad. This project revolves around two real life case studies. So this project is titled "The Role of Corporate Communication in Handling Organizational Crisis' revolves around two real life case studies. It highlights the specific areas where the organization has put in its efforts in managing the two different disasters that happened in the recent past. The first case happened in 2005, when the biggest offshore platform belonging to the World's Most Admired Company was hit by a vessel whereby a catastrophic fire engulfed the platform which was lost forever. In the second case in 2009 , the organization faced a crisis when it was asked to set up itself as a subsidiary unit in Assam. Crisis communication, an extremely important role of Corporate Communication has been explained elaborately with the two cases studies in the report.
\end{abstract}

Keywords: Crisis management; Crises; Disaster; Media; Public relation; Corporate communication

\section{Introduction}

A crisis is any event that leads or is expected to lead to an unstable or dangerous situation affecting an individual, community, organization or whole society. Crises are believed to bring about negative changes in the security, economic, political, societal, or environmental affairs, especially when they occur abruptly, with little or no warning. More loosely, it is a term meaning 'a testing time' or an 'emergency event'. "Communication, organization and crisis". Communication Yearbook 21: 231-275 say that crises have four defining characteristics that are "specific, unexpected, and non-routine events or series of events that create high levels of uncertainty and threat or perceived threat to an organization's high priority goals." Venette argues that "crisis is a process of transformation where the old system can no longer be maintained." Therefore the need for change arises and if change does not take place, the event could more accurately be described as a failure [1]. Risk communication in a High Reliability Organization: APHIS PPQ's inclusion of risk in decision making. Ann Arbor, MI: UMI Proquest Information and Learning.

\section{What is crisis in organizations/industries?}

Crises can strike any company anytime. Be it oil sectors, pharmaceuticals, food and beverage, real estate sector, crises can happen anywhere without any afore mentioned reason. Crises do not discriminate itself based on a company's size or ill repute, and they can hit when a company least expects them. They come in many formsstrikes, layoffs, product tampering, product recalls or allegations of misconduct, but while some of these may seem small, every crisis is highly potential in damaging the name and reputation of a company. Crisis in an organization results in instability of the industry, brings about unhealthy competition and destroys the employee satisfaction and morale in working with the organization. Also, regardless of the severity of the situation, crises pose a serious threat to the companies, their image or reputation to the society and their fiscal health. Some companies emerge from crises unharmed in the eyes of consumers and investors. Johnson and Johnson is an example of one such company. In 1982, Johnson \& Johnson's Tylenol medication commanded 35 percent of the US. But, after it was discovered in the USA in 1986 that its Tylenol capsules had been laced with cyanide and as a result of this, seven people died, Johnson and Johnson reacted in such an effective way that the case is now well-documented as an example of successful crisis management [2]. The factor that determines how a company will withstand a crisis, is the company's ability to response to the situation. Also, crisis is a time when the media targets the organization to the maximum extent. The organization should take care of the fact that during the crisis period, the right message is communicated to the public from time to time. What also happens is that the public forgive accidents, but they do not forgive the organization if it fails to meet the demands of the public and respond to them inadequately. One substantial barrier the company must overcome is the public's perception, because it is a well-known fact in the public relations field that perception is, indeed, reality. Thus, for the continuity of development, the need for public relations roles in management of crisis cannot be over stated emphasized.

\section{What is crisis management?}

Crisis Management is indeed an inevitable Public Relation tool in situations where the brand/company is going through a tough

*Corresponding author: Debatree Saha, ABP Pvt Ltd, Prafulla Sarkar Street, Kolkata, West Bengal, Kolkata, India, Tel: 9654765751; E-mail: debatreemjmc@gmail.com

Received November 20, 2013; Accepted January 09, 2014; Published January 15,2014

Citation: Saha D (2014) The Role of Corporate Communication in Handling Organizational Crisis with 2 Case Studies from the Petroleum and Natural Gas Industry. J Mass Communicat Journalism 4: 173. doi:10.4172/2165-7912.1000173

Copyright: @ 2014 Saha D. This is an open-access article distributed under the terms of the Creative Commons Attribution License, which permits unrestricted use, distribution, and reproduction in any medium, provided the original author and source are credited. 
time with its image in the society. There are situations where a brand/ company knowingly or unknowingly gets into some trouble and in such cases crisis management is the only way in which the business can be protected. During the time of crisis, the biggest challenge for any organization is to identify the right media vehicle and the correct time of communication so that it has maximum impact. If one misses out the right time, it is difficult to have the desired impact. Also, the company should try not to be over persistent as it may give a wrong message to the public. So, choosing the right media to convey the right message at the right time to have the right impact is the biggest challenge of crisis management. Also, brand building is a serious and continuous process which is not comprehended by most organizations. It is used more as a tool for personal image building. The various strategies and communication media which can be utilized for image building are a dynamic process but change is not easily accepted in current PSU culture. During the time of crisis, time is of the topmost criteria, so it is essential for companies to plan ahead. In a world where the wrong splitsecond decision can cost a company millions in negative publicity, not being prepared is not worth the risk - to executives or the companies they work for. Many companies today recognize this and have in place a crisis communication plan that outlines the steps to be taken during the first few hours of a crisis. They spell out the who, what, when, where and how the company should deal with the crises. The best plans produce many of the materials necessary ahead of time, including initial official statements, press releases, fact sheets and backgrounders so that the missing information simply must be inserted and the materials are ready to go. A good crisis plan is "everything you need in one place so you don't have to search - because you may not have time to search." Tools such as giving positive advertisements or an advertorial which explains the situation/doing a comic act on the situation etc, holding promotions on hoardings and trying to include celebrity in the advertisements are ways to continue to function effectively during the crisis period. Through Media Relations, the company can also ensure that positive articles are published about the company so that the image in the public eye can be improved [3]. In a nutshell crisis management involves Identifying the crisis, planning a response, responding to a sudden event that poses a significant threat to the firm, limiting the damage and drawing boundaries, selecting an individual and team from the management to deal with the crisis, coordinating with the media and delivering right and positive message to the audience at the right time and finally identifying measures and resolving a crisis.

\section{The crisis management plan}

A crisis management plan is necessary because of the faster flow of news and information than ever. So companies must be in a position to quickly answer questions and allegations about the ongoing crisis. Many times it happens that organizations get crisis management wrong than doing it right. When the situation arises, most companies stay unprepared and tend to handle the situation inefficiently. Organizations who waste valuable time at the beginning of a crisis can expect to see a monetary loss in terms of revenue and stock prices. Since the Tylenol crisis that happened in the 1980s where unknown parties tampered with bottles of the product, the concept of crisis management became all the more prominent. Since then it has become a specialized activity in the domains of communications and public relations. Companies have now come to recognize crisis communications capabilities as a vital part of their risk management and business continuity strategies. As a part of crisis management plan, organizations prepare crisis management plan and find out ways to execute it and come out of the disaster. Organizations prepare contingency plans in recognition of the fact that things can go wrong anytime. Its aim is to minimize the unforeseeable events and bring the company back to normal operations after the crisis.

The contingency plan involves

- Preparing for predictable crisis

- Preparing for unexpected and unwelcome events.

The contingency plan identifies alternative courses of action that can be taken if circumstances change with time. It includes programs for improving the business in long term once the situation is handled and the issues are resolved. Also, contingency plan contains detailed standby procedures to enable continuation of essential activities and services during the emergency period.

The steps involved in drawing up a contingency plan include:

- Recognise the need for contingency planning

- Identify possible contingencies-all the possible adverse and crisis scenarios

- Specify the likely consequences

- Assess of the degree of risk to each eventuality

- Determine risk strategy to prevent a crisis and to deal with a crisis should one occur

- Draft the plan and identify responsibilities

- Simulate crises and the operate of each plan

The strategies an organization should adopt to handle crisis and maintain the reputation of the brand includes

- Positive write ups in publication's editorial

- Advertorials/Ads denying the allegations

- Event appearances by higher management

- Internal Dealer meets to clarify the situation

\section{Corporate communication and crisis management}

Crisis communication is sometimes considered a sub-specialty of the public relations profession that is designed to protect and defend an individual, company, or organization facing a public challenge to its reputation. These challenges may come in the form of an investigation from a government agency, a criminal allegation, a media inquiry, a shareholders lawsuit, a violation of environmental regulations, or any of a number of other scenarios involving the legal, ethical, or financial standing of the entity [4]. Corporate Communication includes public relations, crisis and emergency communication, corporate citizenship, reputation management, community relations, media relations, investor relations, employee relations, marketing communication, management communication, corporate branding, image building and advertising. Decisions of crisis management are analyzed emphasizing the importance of efficient corporate communication in crisis planning and strategic management process. Efficient corporate communication problem still remains relevant in social, economic and managerial aspects. There is always a need to manage communication process in business, to generate communication ideas and crisis prevention and management. The understanding of corporate communication is broadly based on two aspects: to describe relationship between social environment and business expression, i.e., management of corporate communication system and maintenance of company's business strategy, i.e. implementation of practical decisions. 


\section{Methodology}

This study was designed to find out the role played by Corporate Communication team in any organization to handle organizational crises. The study as is supported by two cases, elaborately talks about how efficient corporate communication is in handling disaster or unforeseen incidents in an organization. The section dealing with the role of Corporate Communication has been written after compiling personal interview inputs from Corporate Communication heads of Real Estate and specifically Petroleum Sector. The role of the team in the case studies has been carried out in real life situations especially during the occurrence of the event. Out of the two cases presented, I was involved in the second case and was working as a Corporate Communication team member when the crisis evolved as a decision to set up the organization as a subsidiary unit in its Assam asset. The methodology also deals with primary research where the opinion from different management personnel and especially Corporate Communication department via personal interviews and questionnaire have been studied. The secondary data is collected from periodicals, articles, newspapers, annual reports, press releases etc.

\section{Case study}

Any organization, be it in any sector, petroleum, retail, pharmaceuticals, FMGC etc., may undergo a crisis situation anytime knowingly or unknowingly. It then becomes the responsibility of the organization to find out means and come out of the crisis. The Corporate Communication team in any organization takes up the responsibility of bringing out the organization from the crisis situation and retain a positive image in the eyes of the stakeholders and audience. A reputed PSU brand in the list of petroleum and natural gas sector and listed in the fortune 500 companies and in World's Most Admired Company', has gone through two critical crisis situation in the past few years, once in 2005 and again in 2009. This Fortune 500 Company faced a massive disaster in its offshore oil drilling rig. In 2005, the biggest offshore platform was hit by a vessel whereby a catastrophic fire engulfed the platform which was lost forever. In this tragedy 8 people lost their lives but around 355 were rescued by Offshore Vessel, Helicopters, Indian Navy and Coast Guards and brought ashore safely. The fire was triggered after a vessel collided with one of the four platforms and the platform was destroyed within a period of 2 hours of fire. The property loss faced by the organization is 300Million USD. In the accident one was the Multi Purpose Support Vessel (MPSV) that caught fire and later sunk on August 1, 2005, 12 Nautical miles from the coast. In order to control the further loss and hindrance to environment, the subsurface safety valves were closed [5-8]. The Corporate Communication department of the organization made an active participation during the mishap. It constantly kept in touch with the media and the families of the employees who lost their lives. Information and every minute update of the accident were sent to the media for its immediate release. The department on behalf of the organization made a public announcement regarding compensation to be paid to the family of the deceased. In order to maintain the reputation and image of the organization, Collectives from the accident zone have been asked not to take any action which may adversely affect the oil and gas production from the Offshore and thereby the national economy at this critical juncture. To avoid panic in the situation, helpline numbers of the onshore zone was immediately circulated through all media channels. The meeting of the then Petroleum minister with representatives of Officers and Employees Associations and discussions regarding follow up measures with CMD were effectively covered by the media and regular press releases came up till the situation was handled and panic was over.
On getting information about the accidents the Communication team immediately contacted the control room to verify and obtain details of the accident. Thereafter a press brief was drafted and with approval of concerned Director or CMD shared with the media so as to keep them fully informed of the accident and to prevent any misreporting. Press conferences were organized at regular intervals where Minister and CMD briefed the media persons and clarified all issues raised by them.

Corporate Communication team also kept in touch with the families of the people who were affected so as to dispel their fears and anxiety to some limit. During entire period of save and rescue operations launched by the company, Coast Guard and navy, kept compiling information which was released to media on a daily basis.

Compensation to victims was provided at earliest and this was widely shared with stakeholders to inform them about organization's concern for the victims. With efficient managerial and communication strategies and effective handing of press and media coverage of the disaster, the organization was taken out from the crisis and is reputation and functioning in the eyes of stakeholders, employees and people in general were strongly managed.

Still there were few constraints faced by the communication department while handling the crisis. Timely and sharing of complete information by the various departments and sources was not there thus time and productive energy in gathering information was wasted. Corporate Communications was also not treated as a mandatory part of disaster management process and generally people were hesitant about sharing information with media thus mis-representation of facts in news. Media was also too eager to splash news and sometimes creating panic among the families and friends of people affected by disaster.

This flagship public sector enterprise and India's highest profit making corporate in spite of making profit, faced a massive crisis in its Assam Asset in 2009. As a result of this, there tend to be a massive shift in functioning of the organization's Assam Asset when it was decided to set up the asset as a subsidiary company for the overall improvement of crude oil production and the development of the Assam economy. This adamant attitude on the subsidiary move on Assam Asset of the organization has triggered adverse reaction on the general public. Economist Adam Smith ascribed an organization's progress to labour, labourer, capital and organizational determination, and all these factors are present in Assam asset. Then why there is unfair behavior to productive Assam asset? As the subsidiary issue reached the Assam population they thought that the organization will become privatized going into the hands of the capitalists. Questions came up that why there has been misjudgment with the Assam asset, where the oldest oil fields came under severe threat of privatization. Different sections of the society including a section of the employees in Assam Asset and also the conscious section of the society have already expressed their displeasure at the reports and have resolved to prevent any such move by the government. Even the fate of the youths to be employed with the company was hanging in balance due to such a decision of the petroleum ministry. Oil wells in Assam oil fields were successively handed over to private parties, which was yet to yield the desired results. The organization had also made it clear that at no stage was there any proposal for separating Assam asset. The option of forming a subsidiary body was only at a conceptual stage and any such move can only be taken after the consent of the employees and the approval of MoPaNG (Ministry of Petroleum and Natural Gas) along with the stakeholders and the centre [9]. 
Due to constant decrease in the production of oil and gas in Assam, the Petroleum Ministry was planning to create a separate subsidiary of the enterprise for oil and gas. As most of the population of Assam is dependent on the industry which contribute immensely towards the growth of the economy, such a plan by the Petroleum Ministry was opposed by the local people as they felt that this step was another move towards privatization. As a result of this, a constant 96 hour strike was called which resulted in delayed work and loss in production. This is an unique enterprise which needs to operate all throughout the time because as it is involved in production of oil and gas, the wells cannot be left idle and constant drilling needs to be done. The major problem with the North-Eastern States is that they treat strikes as a solution to every problem, but it is actually not a solution but it leads to increased problem as frequent strikes lead to delay in workflow resulting in irreparable damage to the reservoir which ultimately results in reduction of production in the long run. There was unavailability of transportation during the bandh and it also became difficult to address the media and to give press and news releases at that time. This issue did not remain confined within the organization and as it touched the political parties it also resulted in violence. Two officers were beaten up in Sivasagar and some vehicles were also damaged. The officers were also threatened which altogether led to an overall crisis situation. The situation worsened more because there was non-existence of transportation and media persons were not able to arrive on time and news failed to be conveyed to them.

\section{Role of corporate communication}

It was a real tough time for the corporate communications to handle this situation because once they were listening to the media and again to the management and so failed to convey the accurate information to the media. It was also difficult for them to control the crisis because the local newspapers did not listen to the enterprise and they were only concerned about the local grievances [10-12]. So the need to inform the national media was felt so that the right news could reach out to the public on time. The communication department also had a tough time in managing the information and conveying the accurate information to the media and the public. So there was a constraint in the information flow and since Nazira-Sivasagar was under strike, through telephonic conversation and internet news was passed on to the liaison office at Guwahati where press releases were arranged to be sent to the media. The situation was very tensed and volatile due to the hostile conditions that took place.

\section{Discussion}

The overall crisis management was satisfactory looking at the prevailing infrastructure and local conditions. All parts of the NorthEastern states are not as developed as the other metropolitan cities of the country. So they always do not provide adequate infrastructure to run an organization and in this case there was optimum utilization of the available infrastructure done by the corporate communications department for which they were able to bring out the organization from the situation. In both the cases, all possible efforts were made by the corporate communications to reach out to the media, the government, the press and the local people through different channels like interviews, press releases, telephonic conversations etc. In the second case, though there was disturbances created due to the strike and they could not reach out directly to the media yet they made all possible efforts to reach out to them and even communicate with the government and the local people to provide them information. The information channels were successfully kept alive during the crisis situation and were utilized in the best possible manner. There was a complete open communication scenario and it always kept a track that wrong information is not conveyed to the people. Corporate Communication Department successfully galvanized the success of the national media and the government of Assam. The local media were busy listening to the local people and they did not bother what the organization had to stay so they communicated well with the national media and conveyed their message to the country. After the strike got over, comprehensive dialogue process was initiated and was successfully carried on. Barring few incidents of strikes and demonstrations, the situation remained normal afterwards. Things came down to its normalcy and the organization in this respective asset started functioning as it was earlier. There was no further disturbance created by the people as they were happy with the decision taken by the organization not to form a subsidiary body but the media kept on speculating about the fate of the subsidiary for months to come which could not be controlled. So to close the matter once and for all, a press release categorically denying any further move for subsidiary formation is carried in all newspapers.

\section{Conclusion}

- Corporate Communication must be linked closely to the company's overall vision and strategy. Successful companies connect communication with strategy through structure. Any company's corporate communication team plays an important role in defining a corporate mission and communicating that to the external and internal constituents.

- Internal corporate communication not only conveys organizational messages to its employees, but also makes sure that the message is not misinterpreted and is rightly understood and well accepted. Herein, lies the success of internal corporate communication. Also, choosing the right channel is an essential pre-requisite for successful communication.

- Crisis communication is a tool of Corporate Communication that becomes highly active when any organization goes through a crisis or disaster.

- From the above case studies, it becomes relevant that the first step in preparing for a crisis is understanding the basic fact that any organization, no matter what industry or location it is in, can find itself involved in any unforeseen situation.

- People in charge of corporate communication should set up a brain storming session with the most senior managers and representatives of the area who are most likely to be affected by the crisis. Brain storming sessions should allow participants to be open minded, creative in their views and to work together and develop strategies to tackle the potential crisis. Organization on behalf of the crisis communication needs to determine which constituencies would be the most affected.

- The strategies that an organization should adopt to maintain the reputation of the brand includes positive write ups in publication's editorial, advertorials/ads denying the allegations, event appearances by higher management, meetings to clarify the situation.

- So understanding the causes behind the crisis, acquiring name and contact information of the crisis team, finding out the most affected constituencies, planning a road map to handle organizational crisis and carrying out effective internal and external communication with the employees, management, media, stakeholders, investors and consumers in order to maintain the reputation and image of the brand to the outside world becomes effective strategies of crisis communication for handling organizational crisis. 
Citation: Saha D (2014) The Role of Corporate Communication in Handling Organizational Crisis with 2 Case Studies from the Petroleum and Natural Gas Industry. J Mass Communicat Journalism 4: 173. doi:10.4172/2165-7912.1000173

Page 5 of 5

\section{References}

1. http://iml.jou.ufl.edu/projects/spring01/hayes/.

2. Weiner (2006) March/April.

3. Bernstein 2013.

4. Barman (2013) Role of Corporate Communication in managing disasters in petroleum and natural gas sector.

5. Dikshit 2013
6. Parvatham 2013.

7. Valackiene 2010

8. http://en.wikipedia.org

9. Disaster in Offshore Oil Field in India in 2005.

10. Controversy over setting up the Oil Industry's Assam Asset as a subsidiary Unit 2009.

11. Pathak 2008.

12. Hindu 2005. 